\title{
A Strategy to Optimize Recovery in Orthopedic Sports Injuries
}

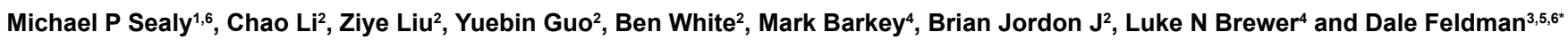

${ }^{1}$ Department of Mechanical and Materials Engineering, University of Nebraska, Lincoln, NE, USA

${ }^{2}$ Department of Mechanical Engineering, The University of Alabama, Tuscaloosa, AL, USA

${ }^{3}$ Department of Biomedical Engineering, University of Alabama at Birmingham, Birmingham, AL, USA

${ }^{4}$ Department of Aerospace Engineering and Mechanics, The University of Alabama, Tuscaloosa, AL, USA

${ }^{5}$ Department of Metallurgical and Materials Engineering, The University of Alabama, Tuscaloosa, AL, USA

${ }^{6}$ Surface Integrity LLC, Birmingham, AL 35203, USA

\begin{abstract}
An important goal for treatment of sports injuries is to have as short a recovery time as possible. The critical problem with current orthopedic implants is that they are designed to be permanent and have a high complication rate $(15 \%)$ that often requires removal and replacement with a second surgery; and subsequently a second rehabilitation cycle. This study tests the feasibility of having a device that provides the needed mechanical properties, to promote healing for a specified amount of time and then degrades away to shorten recovery time. The specific strategy was to create a surface layer on a degradable metal alloy with a controllable degradation rate. Previous studies have shown the feasibility of using surface treatments to alter the surface integrity (i.e., topography, microhardness, and residual stress) leading to increased fatigue strength and a decreased degradation rate. This study was an extension of these previous studies to look at the changes in surface integrity and mechanical properties initially as well as the degradation over time for two surface treatments (shot peening and burnishing). Although the treatments improved initial properties and the burnishing treatment slowed the degradation rate, the faster degradation of the base material in vitro (compared to previous studies) probably reduced the overall impact. The study helped support the feasibility of this approach by showing the ability of the surface treatment to modify surface integrity, initial mechanical properties, and degradation rate; the degradation rate of the base material used needs to be slower and/or the surface treatment needs to create a bigger change in the degradation rate. Further it ultimately needs to be shown that the surface treatment can produce a material that will allow orthopedic devices to meet the required clinical design constraints in vivo.
\end{abstract}

Keywords: Orthopedic sports injuries; Orthopedic devices; Internal fixation; Degradable implants; Degradable metals; Magnesium based metals; Implant design

\section{Introduction}

The goal for treatment of sports injuries is typically to return the athlete to the activity as soon as possible. In this article, the focus is on orthopedic sports injuries that result in breaking of bone or tearing away tissue (tendons or ligaments) from attachment to the bone, although it would be similar for non-sports related orthopedic injuries. Also, the focus is on injuries severe enough to require implanted hardware to stabilize the injury enough so it can heal.

Optimization of clinical treatment in this case normally means shorten as much as possible the healing time to regain mechanical integrity (fracture healing or strength of attachment) as well as shorten the rehabilitation time to return to pain free movement with the needed strength and flexibility. Current clinical treatment is typically metal devices (plates, pins, screws, anchors, wire, etc.). The main problems with these devices are: (1) The high complication rates (15\% for internal fixation devices); and (2) That the designs interfere with healing; lengthening the rehabilitation time [1-6]. Many of the complications (e.g., refracture of the bone) can be reduced by speeding healing. In clinical practice, implants are removed $(80 \%$ of the time in many cases) to speed healing and reduce long-term complications $[2,3]$. This typically requires a second rehabilitation cycle and in many cases leaves holes in the bone, which increases the susceptibility to refracture.

The strategy employed in this study is to have a design that can provide the needed internal fixation (stability of attachment) while promoting healing for a specified amount of time (depending on the type of injury and the patient healing rate) and then degrade away. This would eliminate the need to remove the device; leaving a functional repair that is as close to the original structure as possible. This would require not only healing while the device is in place, but also healing to replace any voids created as it degrades. In this case, a surface layer was created with a controllable degradation rate that is thin enough that degradation through the layer would not significantly alter mechanical properties.

There are many strategies that can be used to speed healing including stem cells, growth factors, and electrical stimulation. From a device standpoint, the more loading that can be placed on the tissue (typically bone in this case) without rebreaking the faster the healing will occur. From a design perspective, the stiffer a component is, the higher the percent of the load it is capable of handling. Choosing a material that has a modulus closer to bone (clinically used metal implants have 10 to 20 times higher modulus than bone) [7] as well as degrading away both serve to increase the loading on the bone.

This study will examine the potential of a Magnesium (Mg) alloy to meet these design constraints. $\mathrm{Mg}$ alloys have a modulus only two

*Corresponding author: Dale Feldman, Department of Biomedical Engineering, University of Alabama at Birmingham, Birmingham, AL, USA, Tel: 205 9348426; E-mail: dfeldman@uab.edu

Received June 03, 2017; Accepted June 15, 2017; Published June 22, 2017

Citation: Sealy MP, Liu Z, Li C, Guo Y, White B, et al. (2017) A Strategy to Optimize Recovery in Orthopedic Sports Injuries. J Bioanal Biomed 9: 144-151. doi:10.4172/1948-593X.1000169

Copyright: @ 2017 Sealy MP, et al. This is an open-access article distributed under the terms of the Creative Commons Attribution License, which permits unrestricted use, distribution, and reproduction in any medium, provided the original author and source are credited. 
times that of bone with mechanical strength 2-6 times that of cortical bone [8]. The problem with $\mathrm{Mg}$ alloys currently under investigation is that they degrade too fast; losing mechanical properties too quickly for most orthopedic applications [8]. There is also concern that the fatigue strength may not be sufficient for some applications [9]. This study will show the feasibility of slowing the degradation of an $\mathrm{Mg}$ alloy enough to make it useful for orthopedic applications; particularly ones that require stability for at least a few months. The degradation rate, in this case, is the decrease in mechanical properties over time. The mechanical degradation is controlled mostly by material degradation, since both the stiffness and load carrying ability are proportional to the cross-sectional area.

Although there are different ways to slow the degradation of an $\mathrm{Mg}$ alloy, this study will focus on using surface treatments to create a surface layer with a decreased degradation rate that can also increase fatigue strength. For many other applications, it is known that modifying the surface integrity of a material can affect both mechanical and degradation properties. Several studies have shown the effects of Laser Shock Peening (LSP) [10-17], burnishing [18-24], and shot peening [25-33] on corrosion and fatigue performance. Specifically, techniques to mechanically induce increased residual stress in a surface layer have been shown to increase fatigue strength and slow the degradation rate.

The objective of this study was to show the feasibility of using surface treatments (shot peening and burnishing) to increase the fatigue strength and slow the degradation rate of an $\mathrm{Mg}$ alloy enough to make it useful for the orthopedic sports injuries described earlier. Specifically, the goal was to characterize changes in surface integrity (i.e., topography, microhardness, and residual stress) and the resultant changes in mechanical properties initially as well as after in vitro degradation. Part of this study was also to begin the process of determining the relationship between surface treatment and degradation rate.

\section{Materials and Methods}

Magnesium Calcium ( $\mathrm{MgCa}$ ) implants were processed with the mechanical surface treatments burnishing and shot peening to impart favorable mechanical properties that would impede corrosion and loss of structural integrity. After corroding in Hank's solution, orthopedic pins were subjected to three-point bending in order to quantify the loss of structural integrity over time. The following sections identify the materials and methods for the surface treatment, surface integrity characterization, degradation testing, and mechanical behavior.

\section{Sample preparation}

Square $\mathrm{MgCa}$ alloy (0.8 wt \% calcium) pins were machined from $38.1 \mathrm{~mm}$ diameter round bar stock to the final dimensions of $6.35 \times$ $6.35 \times 28 \mathrm{~mm}$ (Figure 1). The round bar was milled to rectangular bricks and sectioned into pins using a diamond saw under flood coolant conditions. Once sectioned into pins, each face was ground with 1200 grit silicon carbide pads. After grinding, shot peening and burnishing were applied to the external surfaces (excluding the ends). There were 15 samples for each surface treatment condition: Three for surface integrity characterization, nine for corrosion and mechanical degradation tests, and three for fatigue tests. The elastic modulus of MgCa was approximately $45 \mathrm{GPa}$ and the ultimate compressive strength was $154 \mathrm{MPa}$. More mechanical properties related to this material can be found in Guo et al. [34].

\section{Surface treatment procedures}

Shot peening: Shot peening is a mechanical process where media (e.g., metal, ceramic, or glass beads) is shot at high velocity to deform the surface of a work piece (Figure 2a). The plastic deformation from shot peening induces deep compressive residual stresses below the surface. The stochastic nature of the peening process results in a random distribution of craters that increases the surface roughness. The critical process variables that affect surface integrity are the bead diameter, bead material, air pressure, and coverage.

In this study, glass beads were shot at 20 psi and 80 psi for approximately $30 \mathrm{~s}$ on each surface. The distance between the target and nozzle was approximately $10 \mathrm{~mm}$ and the number of reversals (i.e., passes) was approximately 20 . Glass beads were chosen as opposed to steel beads to prevent contamination of the surface that could have resulted in galvanic corrosion. The average bead diameter was between 0.25 and $0.425 \mathrm{~mm}$.

Burnishing: Burnishing is an effective surface treatment for large area implants, such as orthopedic plates used for trauma fracture fixation. Ball burnishing is a mechanical process where a hydrodynamic ball applies a force in rolling/sliding contact to plastically deform the surface of a workpiece (Figure 2b). Although the surface roughness typically decreases after burnishing, the plastic deformation induces deep compressive residual stresses well below the surface. The critical process variables that affect surface integrity are burnishing force and ball diameter.

In this study, a $12.5 \mathrm{~mm}$ diameter ceramic ball (Ecoroll HG12.5) was used to burnish the surface of $\mathrm{MgCa}$ at loads of 10 and $40 \mathrm{~kg}$. A Cincinnati Arrow $500 \mathrm{CNC}$ machine was used to conduct burnishing

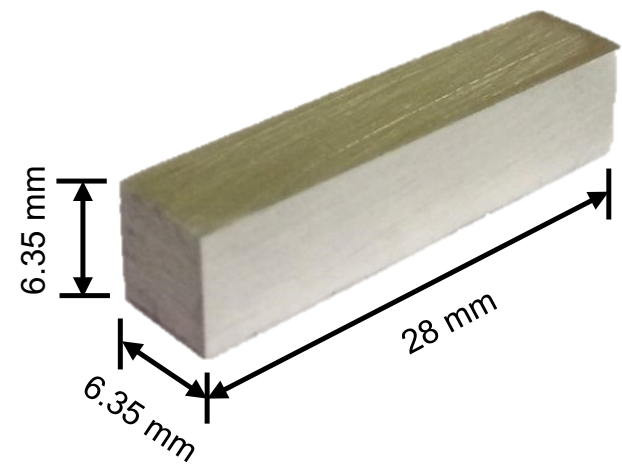

Figure 1: MgCa pin used in corrosion and three point bending studies.

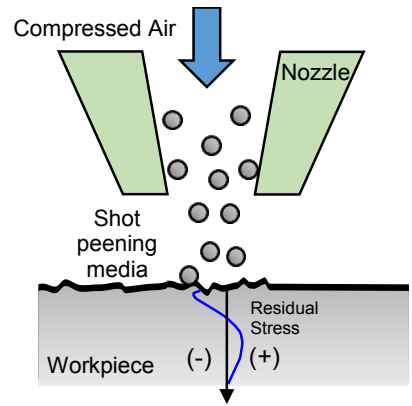

(a)

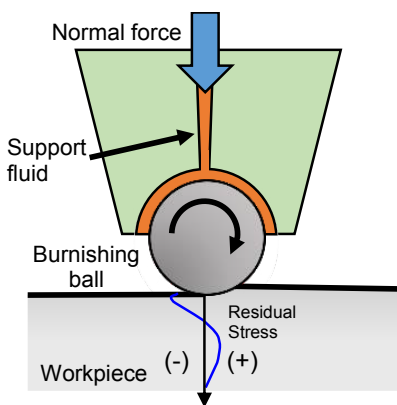

(b)
Figure 2: Process schematics of (a) shot peening and (b) burnishing to impart a favorable surface integrity that can influence stress-corrosion behavior. 
while a load cell measured the applied load. The hydraulic pressure was 0.8 and $3.2 \mathrm{MPa}$. Based on Hertz contact theory, the estimated maximum contact pressures were 2034 and $3223 \mathrm{MPa}$. The feed was $0.1 \mathrm{~mm}$.

\section{Surface integrity characterization}

Surface integrity can significantly affect the degradation rate and subsequent strength of a medical device. Isolating the influence of individual surface integrity metrics on the degradation rate is a challenging problem. Instead, the combined effect of all the surface integrity modifications must be investigated. For example, some of the effects of increasing the surface roughness (increased degradation rate) can be reversed by increasing the hardness and compressive residual stress. In this study, surface integrity was characterized by topography, microhardness, and residual stress. The procedure and results are presented below.

Surface topography: Surface topography can significantly influence the degradation rate. A rougher surface will typically have a higher corrosion rate since the surface area exposed to the solution increases. Surface topography was analyzed using a Keyence VHX Digital Microscope. The scan area was approximately $800 \mu \mathrm{m}$ by $1200 \mu \mathrm{m}$. Roughness (Ra) was measured along the $\mathrm{X}$ and $\mathrm{Y}$ (planar) directions of the surface. Measurements were repeated five times.

Microhardness: Microhardness is another key indicator of degradation rate. Vickers microhardness was measured using a Buehler Hardness Tester on and below the surface. The load was $500 \mathrm{~g}$, and the dwell time was $15 \mathrm{~s}$. The spacing between measurements was approximately $188 \mu \mathrm{m}$. Measurements were repeated three times.

Residual stress: Residual stress is an influential factor that affects the degradation rate and the subsequent strength of a degraded implant. Residual stress was analyzed on and below the surface of an $\mathrm{MgCa}$ implant using a Proto iXRD Reidual Stress Analyzer. A Cobalt-K $\alpha$ source $(0.179 \mathrm{~nm})$ was used at a $20 \mathrm{kV}$ voltage and $4 \mathrm{~mA}$ current. The $2 \theta$ angle was $141^{\circ}$ and the crystallographic plane was 204. Measurements on the top surface were repeated 5 times. The average error was $4.14 \%$. To measure subsurface residual stress, samples were electro-polished in $20 \mu \mathrm{m}$ increments which corresponded to $45 \mathrm{~s}$ of polishing time in the electrolyte. The electrolyte contained $375 \mathrm{~mL}$ of phosphoric acid, 625 $\mathrm{mL}$ of ethanol, and $300 \mathrm{~mL}$ of deionized water. The voltage and current for electro-polishing were $20 \mathrm{~V}$ and 2.6-2.7 A, respectively.

\section{Material degradation testing}

The objective for the material degradation tests was to characterize the degradation rate using immersion at various time points until fully degraded. In magnesium degradation, hydrogen gas evolves with the dissolution of magnesium. In fact, the dissolution of magnesium (i.e., degradation rate) can be determined by measuring the amount of hydrogen gas produced [35]. The overall degradation of magnesium in a neutral or basic solution can be represented by:

$$
\mathrm{Mg}+2 \mathrm{H}_{2} \mathrm{O} \rightarrow \mathrm{Mg}^{2+}+2 \mathrm{OH}+\mathrm{H}_{2}
$$

Therefore, the dissolution of one mole of $\mathrm{Mg}$ (or binary Mg-alloy) corresponds to the generation one mole of Hydrogen gas $\left(\mathrm{H}_{2}\right)$. Since one mole of gas is equivalent to approximately $22.4 \mathrm{~L}$ at standard temperature and pressure and the mass of one mole of $\mathrm{Mg}$ is $24.305 \mathrm{~g}$, the generation of $1 \mathrm{~L}$ of $\mathrm{H}_{2}$ at $37^{\circ} \mathrm{C}$ corresponds to approximately $1 \mathrm{~g}$ of dissolved Mg.

In this study, MgCa pins were placed in Hank's solution to simulate body fluid with sodium bicarbonate as a buffer. The buffer helped maintain a stable $\mathrm{pH}$. The solution was stirred and kept at a constant $37^{\circ} \mathrm{C}$. The solution was changed once a week. After one week, the $\mathrm{pH}$ increased from 8 to 10 . The experimental setup to collect hydrogen $\left(\mathrm{H}_{2}\right)$ is shown in Figure 3. Custom graduated beakers were produced that allowed solution to flow across the sample while capturing the $\mathrm{H}_{2}$ gas. Samples were oriented vertically. Once the chamber filled with gas, the beaker was reset by releasing the $\mathrm{H}_{2}$ and recording the date and time.

\section{Mechanical degradation testing}

The objective for this experiment was characterizing the mechanical degradation rate at multiple time points during a long term immersion test. There were nine samples for each surface treatment condition and an untreated control. Three samples from each condition were removed from the Hank's solution at two time points (1 week and 2 weeks) to measure three-point bending strength. Three-point bending was conducted on an MTS Landmark System (Model 642.10B) under displacement control (Figure 4).

\section{Fatigue testing}

The objective of the fatigue tests was to measure the fatigue life of shot peened and burnished orthopedic MgCa pins. The results were compared to an as-machined pin. Due to the rapid corrosion rate, fatigue data was limited to non-corroded samples. Three-point bending fatigue was performed at $30 \mathrm{~Hz}$ with a maximum load of $800 \mathrm{~N}$ and a

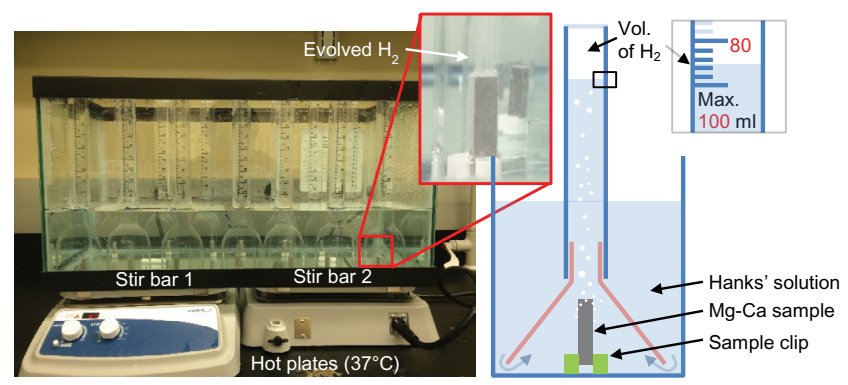

Figure 3: Measuring degradation rate of $\mathrm{MgCa}$ pins in Hank's solution by hydrogen evolution.

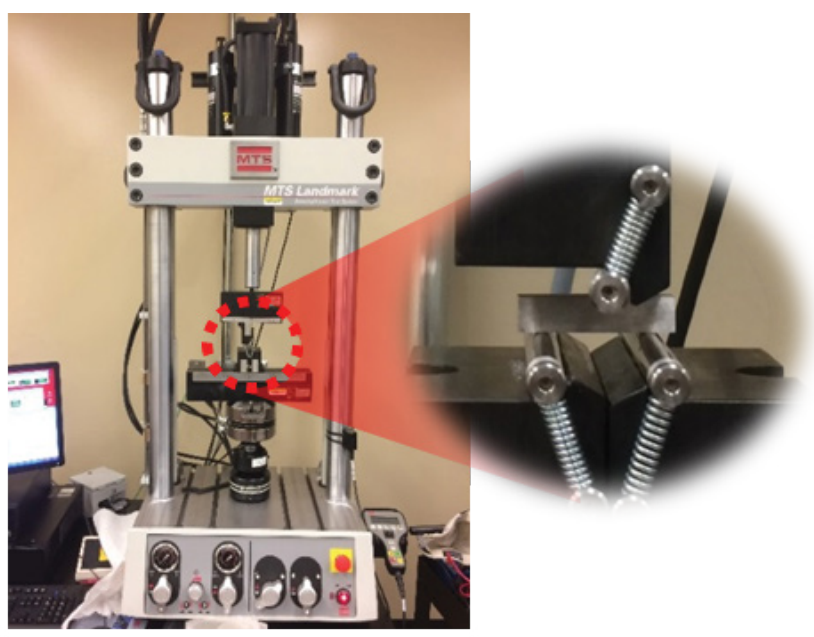

Figure 4: Measuring mechanical degradation using three-point bending strength. 
Citation: Sealy MP, Liu Z, Li C, Guo Y, White B, et al. (2017) A Strategy to Optimize Recovery in Orthopedic Sports Injuries. J Bioanal Biomed 9: 144-151. doi:10.4172/1948-593X.1000169

minimum load of $80 \mathrm{~N}$. Three samples for each condition were tested.

\section{Results}

\section{Surface integrity}

Surface topography: Surface roughness and topography maps from the as-machined, shot peened and burnished samples are shown in Figures 5 and 6, respectively. Error bars indicate the maximum and minimum measurements. As expected, shot peening produced the roughest surface. At a high shot peening pressure $(80 \mathrm{psi})$, the surface roughness $(\mathrm{Ra})$ was 3.5 times that of the as-machined surface. Burnishing smoothed the machined surface as evidenced by the decrease in Ra. It should also be noted that the burnished surface roughness exhibited directionality that can be seen in Figure 6.

Microhardness: Microhardness results are presented in Figure 7. Shot peening and burnishing were found to increase the microhardness over an as-machined sample. The $40 \mathrm{~kg}$ burnished surface exhibited the highest hardness that extended more than $2 \mathrm{~mm}$ below the surface. The hardness was nearly $60 \%$ higher than the as-machined sample in the first $500 \mu \mathrm{m}$. Shot peening at $80 \mathrm{psi}$ and burnishing at $10 \mathrm{~kg}$ also increased the microhardness by approximately $30 \%$ over the as-machined sample in the first $500 \mu \mathrm{m}$. Shot peening at $20 \mathrm{psi}$ did not significantly alter the subsurface microhardness beyond $300 \mu \mathrm{m}$.

Residual stress: Residual stress for the surface and subsurface is shown in Figure 8. Burnishing was the only surface treatment procedure to exhibit a significantly higher compressive residual stress over the as machined samples. Burnishing at $40 \mathrm{~kg}$ extended nearly 150 microns below the surface. The maximum compressive residual stress was approximately $128 \mathrm{MPa}$ nearly $100 \mu \mathrm{m}$ below the surface.

\section{Material degradation rate}

The evolved hydrogen $(\mathrm{mL})$ and the corresponding degradation rate ( $\mathrm{mm}$ /year) for shot peened and burnished MgCa pins are shown in Figures 9 and 10, respectively. The highest degradation rates were typically five to seven days after initial immersion. The magnitude was between 25 and $35 \mathrm{~mm} /$ year $\left(11.9-16.7 \mathrm{mg} / \mathrm{cm}^{2} /\right.$ day) which is considered very high for $\mathrm{Mg}$ alloys. As a general trend, the degradation rates increased in the first week followed by a steady deceleration in weeks two and three.

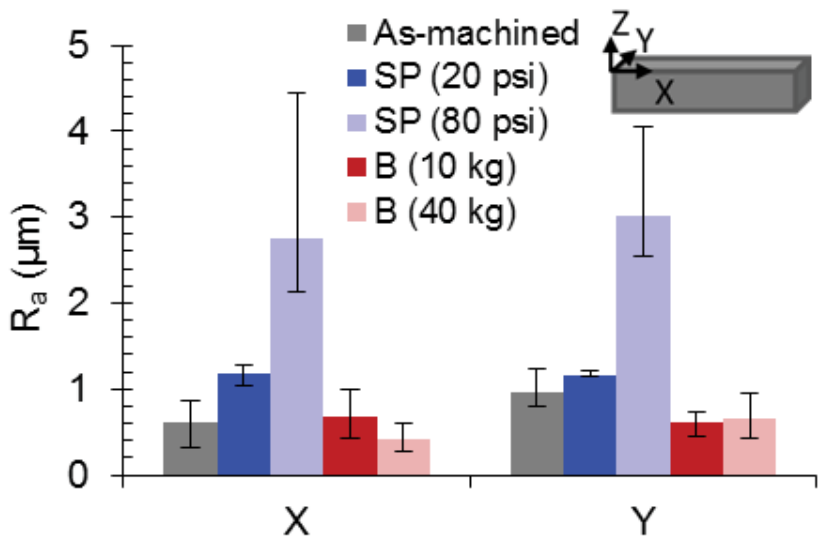

Figure 5: Surface roughness of MgCa pins along the $\mathrm{x}$ - and $\mathrm{y}$-directions after shot peening at 20 and 80 psi and burnishing at 10 and $40 \mathrm{~kg}$.
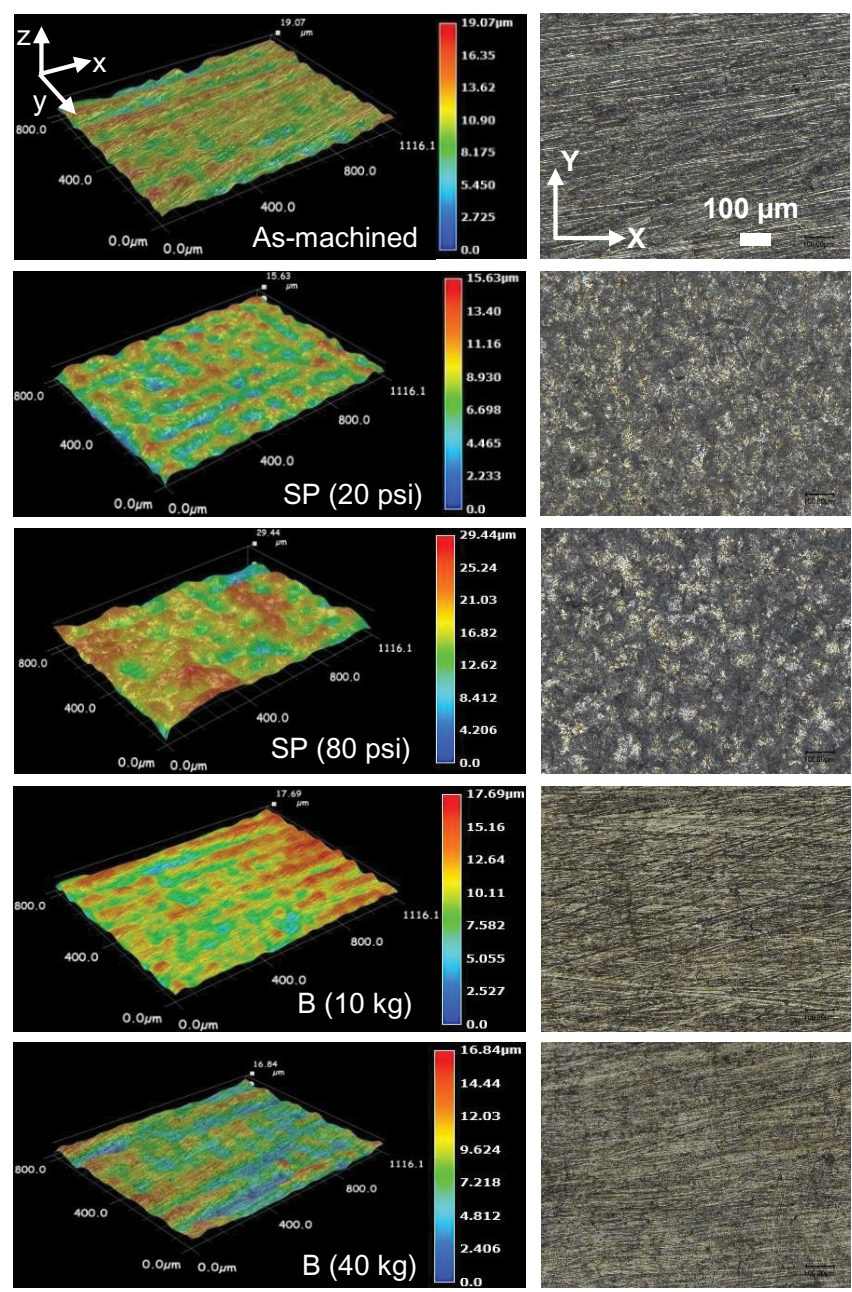

Figure 6: Surface topography maps of $\mathrm{MgCa}$ after shot peening at 20 and 80 psi and burnishing at 10 and $40 \mathrm{~kg}$.

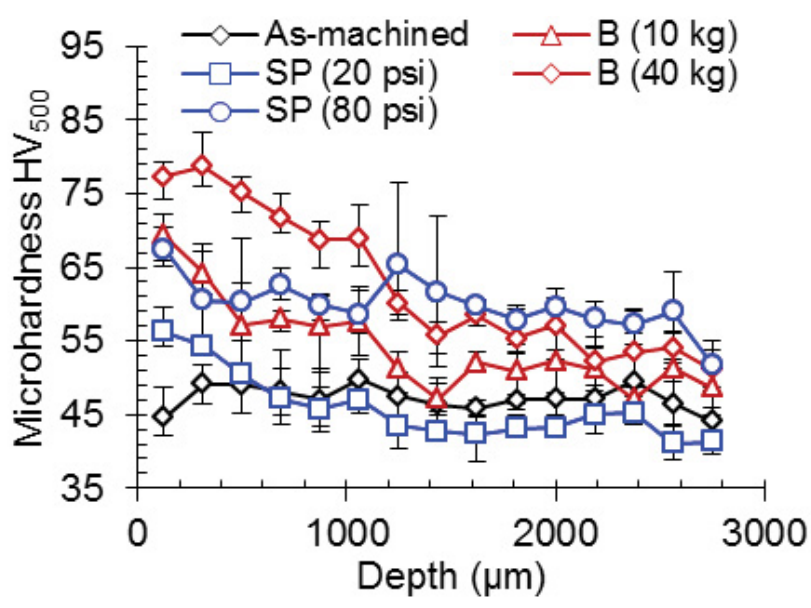

Figure 7: Subsurface micro hardness of $\mathrm{MgCa}$ pins after shot peening at 20 and 80 psi and burnishing at 10 and $40 \mathrm{~kg}$ (Vickers indenter, $500 \mathrm{~g}, 15$ s dwell).

Shot peened and burnished surfaces exhibited different degradation behaviors. For example, shot peening was found to increase the 
Citation: Sealy MP, Liu Z, Li C, Guo Y, White B, et al. (2017) A Strategy to Optimize Recovery in Orthopedic Sports Injuries. J Bioanal Biomed 9: 144-151. doi:10.4172/1948-593X.1000169
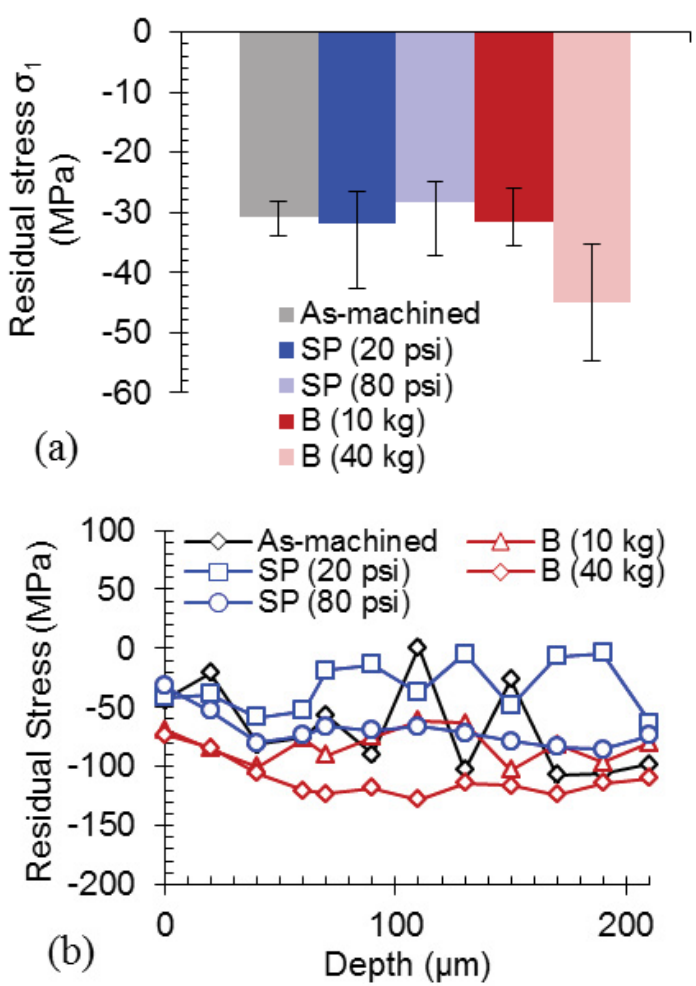

Figure 8: Residual stress in MgCa pins after shot peening at 20 and $80 \mathrm{psi}$ and burnishing at $10 \mathrm{~kg}$ and $40 \mathrm{~kg} \mathrm{(a)}$ on the surface and (b) along the depth $\left(\mathrm{Co}-\mathrm{Ka}, 2 \theta=141^{\circ}, 20 \mathrm{kV}, 4 \mathrm{~mA}\right)$.
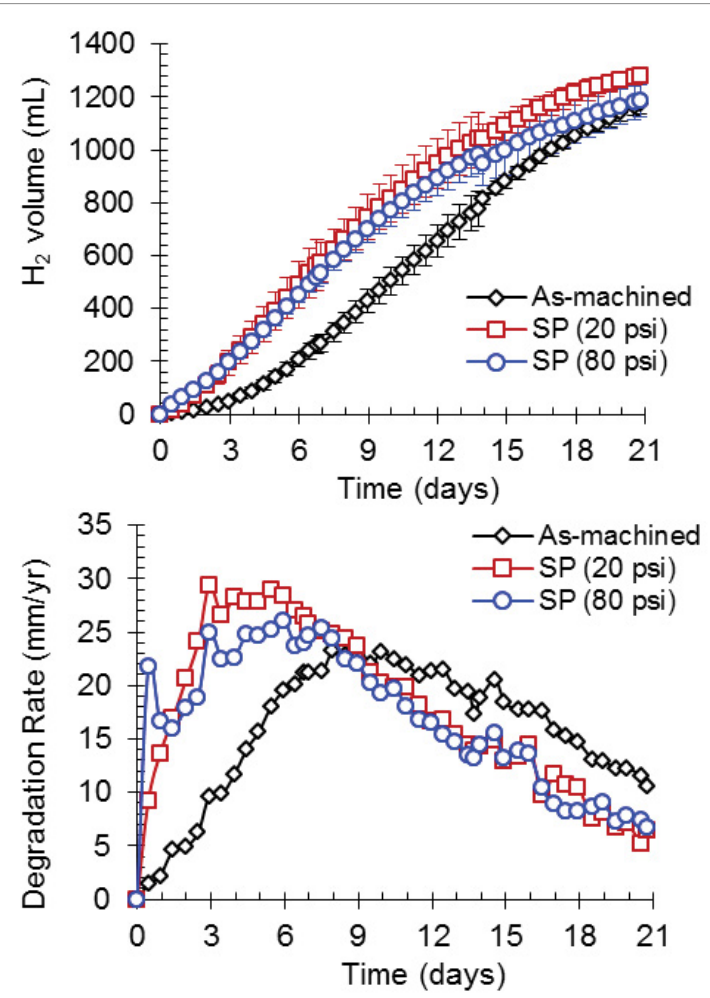

Figure 9: Hydrogen evolution and degradation rate of $\mathrm{MgCa}$ for 21 days in Hank's solution after shot peening (20 and 80 psi).
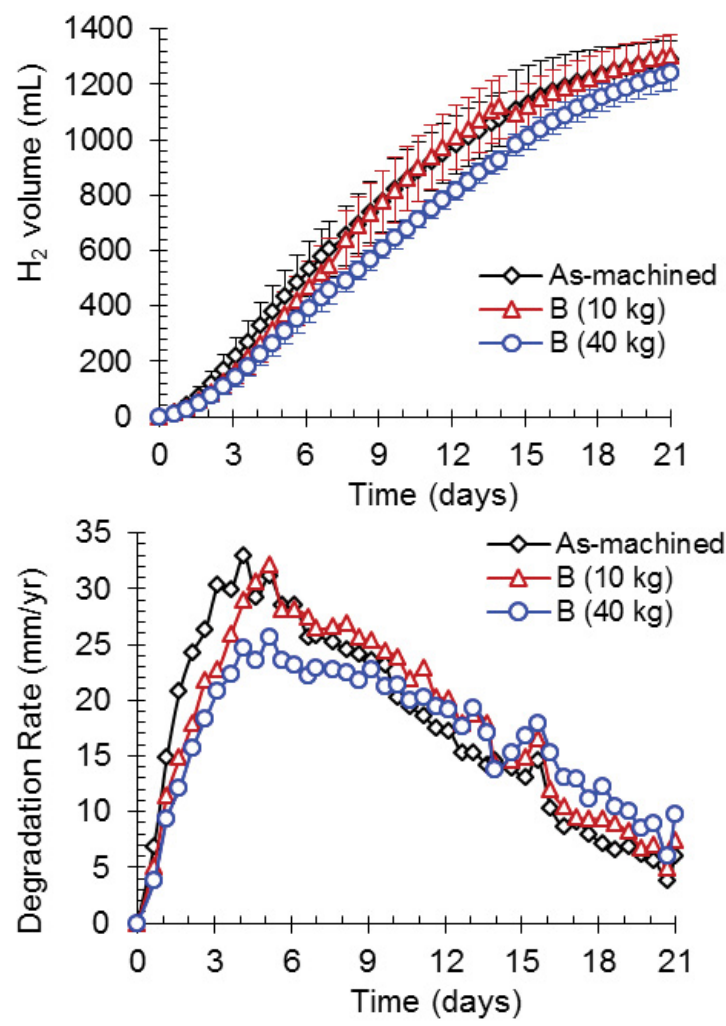

Figure 10: Hydrogen evolution and degradation rate of $\mathrm{MgCa}$ in Hank's solution for 21 days after burnishing (10 and $40 \mathrm{~kg}$ ).

degradation rate to twice that of the as-machined samples in the first week. In weeks two and three, the average degradation rate was nearly $30 \%$ less than the as-machined samples. There was no significant difference among shot peening conditions. For burnishing, the average degradation rate in the first six days decreased by 14 and $29 \%$ over the as-machined sample at 10 and $40 \mathrm{~kg}$ loads, respectively. Weeks two and three experienced equivalent increases in the degradation rate over the as-machined samples.

\section{Mechanical degradation}

The bending strengths of a shot peened and burnished MgCa implants as material degradation progressed for two weeks is shown in Figure 11. Samples that were degraded for three weeks had dissolved to a point where mechanical testing was not feasible. The maximum load (stress) for uncorroded samples ranged between $1.3(150 \mathrm{MPa})$ and $2 \mathrm{kN}(230 \mathrm{MPa})$. Prior to degradation, shot peening had no effect on the strength compared to as-machined samples; the average maximum load was $1.31 \mathrm{kN}$. In contrast, burnishing at 10 and $40 \mathrm{~kg}$ was found to increase the strength 14 and $40 \%$, respectively, over as-machined samples prior to degradation.

In one week, the load carrying capacity of $\mathrm{MgCa}$ pins decreased by 50 and $80 \%$ in 2 weeks (Figure 11a). For shot peening (Figure 11b), the degradation rate and subsequent loss of mechanical strength was faster than the control as evidenced by a greater volume of evolved $\mathrm{H}_{2}$ with a lower maximum strength. As shown in Figure 11c, the burnished samples exhibited higher strengths and lower degradation rates over the control samples after the first week. This indicates burnishing was able to slow the loss of mechanical strength during degradation. After two 

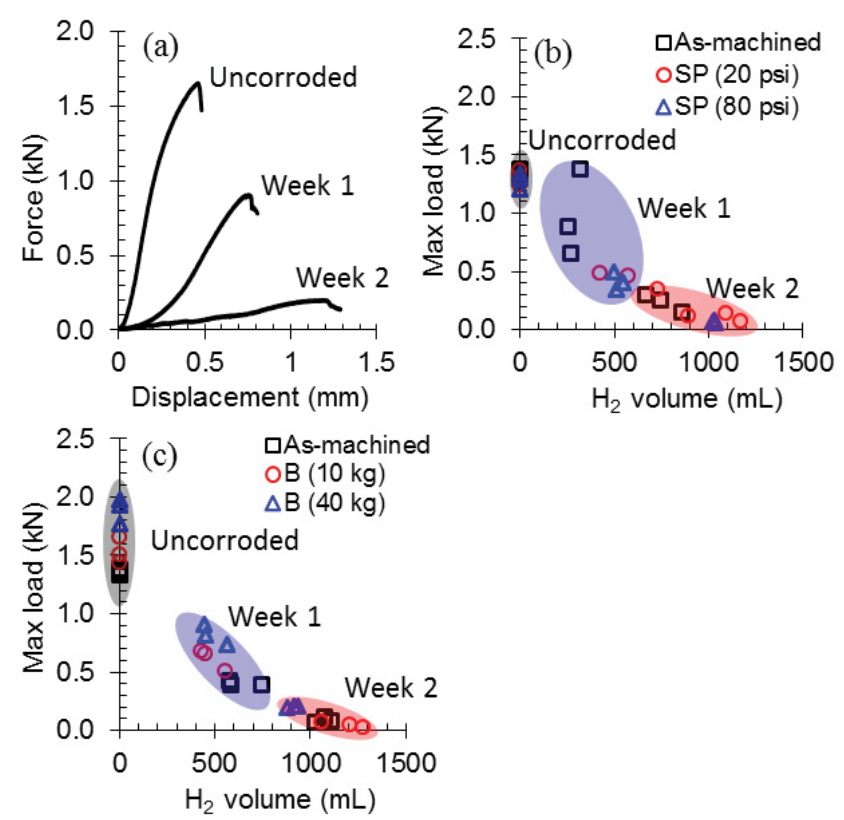

Figure 11: Diminishing load carrying capacity of $\mathrm{MgCa}$ pins exposed to Hank's solution for two weeks: (a) Load-deflection curve, (b) Effect of burnishing, and (c) Effect of shot peening.

weeks, samples burnished at $40 \mathrm{~kg}$ still exhibited a higher strength over the as-machined control. The most significant aspect of these results is that surface treatments have proven to influence the rate at which a magnesium implant's strength diminishes.

\section{Fatigue life}

Each surface treatment condition exhibited a higher fatigue life over the as-machined samples (Figure 12). Burnishing exhibited the highest average fatigue life ranging between 1.2 and 1.6 million cycles. The shot peened samples had more scatter than burnishing. Samples included within the circle did not break. It is expected that the fatigue life from burnishing might be much higher had the test been allowed to continue.

\section{Discussion}

The long-term goal of this line of research is to develop a material that can be used in orthopedic hardware devices to reduce recovery time, after injury, over current treatments. Part of this is to have a material that can be easily tailored to a particular application and the clinician's design constraints. The overall problem is that current treatment is too costly and needs to be more efficient. The cost (time, money, and resources) could be significantly reduced by reducing the complication rate and/or rehabilitation time. Both can be improved by speeding the healing and eliminating the need for removal surgery (requiring a second rehabilitation cycle).

The development of degradable metal orthopedic devices that speed healing, reduce complication rates, and eliminate removal surgery would significantly reduce costs for internal fixation procedures. These current internal fixation devices are used in many procedures with overall costs in the billions each year. There are multiple parts of the body where these devices are used, including: lower extremities $(\$ 1 \mathrm{~B}$ yearly global market), upper extremities ( $\$ 1.4 \mathrm{~B}$ yearly global market), and spine ( $\$ 8 \mathrm{~B}$ yearly global market) [1-6]. This study was designed

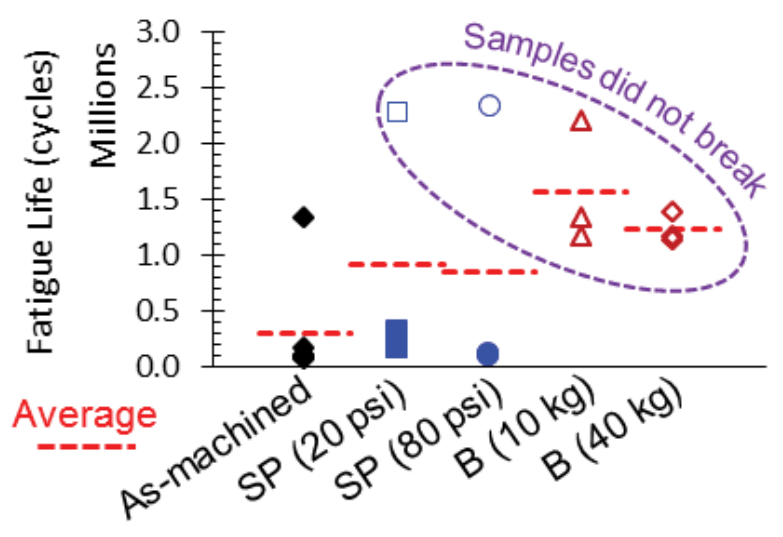

Figure 12: Fatigue life (cycles) of shot peened and burnished $\mathrm{MgCa}$ prior to corroding.

to determine the feasibility of using degradable metals for orthopedic injuries, particularly ones that need to support large loads for at least a few months, while the injury is healing. More specifically, this study determined, if creating a surface layer, with a reduced degradation rate was a worthwhile path to pursue for these applications.

In previous studies, it was shown that surface treatments (laser shock peening and burnishing) can significantly alter the surface integrity and significantly (by up to four orders of magnitude) slow the initial degradation rate of a $\mathrm{Mg}$ alloy (in potentiodynamic corrosion studies) $[10-12,18,36]$. This study was an extension of these previous studies to look at the changes in surface integrity and mechanical properties initially as well as the degradation over time for two surface treatments (shot peening [SP] and burnishing). It was also done to begin developing the model that could predict degradation (both material and mechanical) based on surface treatment. This was to not only determine the relationship between potentiodynamic corrosion rates (initial rates) to in vitro degradation rates but also the relationship between surface integrity changes and changes in degradation rates.

The key findings were that although the treatments improved initial properties and the burnishing treatment slowed degradation rate, the faster degradation of the base material in vitro (compared to previous potentiodynamic studies) probably reduced the overall impact. This also means that the increase in surface roughness with SP seems to have overshadowed the increased residual stress seen for the conditions studied. However, based on previous studies, if appropriate peening conditions are used, the benefit from favourably enhancing the mechanical properties (increased hardness and compressive residual stress) can overcome common premature failures caused by the higher roughness.

Although the study helped support the feasibility of this approach by showing the ability of the surface treatment to modify surface integrity, initial mechanical properties, and degradation rate; the degradation rate of the base material used needs to be slower and/or the surface treatment needs to create a bigger change in the degradation rate. The in vivo corrosion rate is still, however, the critical one and has been studied for the base materials [37]. From a design perspective, the base material probably needs to degrade at a slow enough rates that a $0.5 \mathrm{~mm}$ surface layer lasts at least $1 / 10$ as long as needed. The surface treatment could then create a surface that would maintain a relatively constant 
cross-sectional area and therefore constant mechanical properties for the desired period-then degrade at a faster rate.

The study was not only to show the feasibility of developing the appropriate surface treatment, but also to help show why it has the potential to meet the design constraints while other designs do not. Assuming that a degradable material is required to meet the design constraints, it has been shown that polymers, ceramics, and polymer/ ceramic composites either do not have sufficient mechanical properties initially or lose mechanical properties too quickly; since in many cases they breakdown all at once versus surface erode [7]. That leaves the use of degradable metals, but they also degrade too fast. The question becomes are other techniques of slowing the degradation of the metal more promising than a surface treatment? The two main other competing technologies to slow the degradation rate of magnesium devices are coatings and alloying. Coatings consist primarily of Calcium-phosphate $(\mathrm{CaP})$ or a polymer based material [9,38-45]. CaP coatings have been a research area in orthopedics for over 30 years [43-47]. It is unlikely that this technology will be able to meet all the design constraints for medical devices for short term or even long-term applications. Although there are many different processing techniques being explored, it has not been feasible to produce an adherent layer (without damaging the bulk material) that can protect the bulk material for more than a few months [43]. This is in part due to the tendency of these layers to breakdown unevenly or form cracks, which can prevent them from creating a good seal or negatively affecting fatigue properties. Even though coatings can effectively slow the corrosion rate, they lack the capability to improve the mechanical integrity, i.e. impart a compressive residual stress, increase microhardness, or refine the microstructure of the base material. Furthermore, the limits of coatings are not known and studies suggest they only last a few weeks to 2 months [38-40]. Therefore, with current technology, it has been impossible to either prevent compromising the base material or have a coating that is adherent, stable, and crack free enough to prevent corrosion of the underlying material for a sufficient period. In addition, this strategy does not lend itself well to tailor-ability. Meaning for every application that requires a different degradation rate for the surface layer a new formulation would need to be produced. This would mean not only a longer development time, but a bigger hurdle for the regulatory process.

Although alloying can slow degradation an order of magnitude or more, this still would not be sufficient for most applications $[9,43]$. The addition of rare earth metals has shown the most promise for improving the strength, but biocompatibility remains uncertain $[9,43,48,49]$. In addition, this strategy also does not lend itself well to tailor-ability. Again for every application that requires a different degradation rate a new formulation would need to be produced. This would also mean not only a longer development time, but a bigger hurdle for the regulatory process. Further, the benefit of having the device degrade away at a faster rate once it serves its purpose is lost.

Therefore, surface treatments are the only one likely to meet all these design constraints. The results of this study help show the feasibility of this approach as well as future directions to make this a reality. Specifically, surface treatments that increase residual stress (e.g., peening and burnishing) can significantly increase fatigue strength and are probably necessary to meet the demands of many of these orthopedic systems [9]. Furthermore, surface treatments have the potential to customize or tailor the degradation of an implant to meet the needs for a specific orthopedic application or patient metrics (i.e., bone density, age, sex, etc.), without changing the chemistry; just the manufacturing protocol.
This study was designed to only be a step in the development of a useful degradable metal for orthopedic applications. The biggest limitation is that this is only an in vitro study. It was, however, important to move from initial degradation rates (potentiodynamic corrosion studies) to real-time degradation in order to determine the relationship between the two. Determining the relationship between the two in vitro degradation rates and in vivo degradation is also important for reducing the cost and time of new device development. Another limitation of the study was that the base material selected degraded too fast. This not only made it difficult to examine mechanical degradation over time, but also accurately determine the difference in degradation rate through the surface layer vs. the bulk material.

Also the biocompatibility issues cannot really be addressed without an in vivo study. This was not part of the goals for this study, and has been studied extensively elsewhere [50-56]. The Mg alloy selected, however, was based on favorable results from these in vivo studies.

Since this study is only a step in the process of developing a useful degradable metal for orthopedic applications, there are multiple steps still remaining. It will be necessary to do both in vitro and in vivo studies using slower degrading base materials with a wider range of surface treatments. Not only to establish the relationship between in vitro and in vivo degradation but to have more fully developed predictive models. For device development, it will be important to have predictive models that can select candidate surface treatments to meet design constraints for a particular clinical application. There are also studies needed to commercialize the technology including regulatory approval.

\section{Conclusions}

The study met the objective of showing the feasibility of using surface treatments to increase the fatigue strength and slow the degradation rate of an $\mathrm{Mg}$ alloy enough to make it useful for treatment of orthopedic sports injuries. Additionally, it moved closer to developing a surface treatment that could actually meet the design constraints for these devices in vivo. Further, by showing feasibility, it validated the utility of using this approach, rather than coating or alloying, to control the degradation of the $\mathrm{MgCa}$ alloy.

Although this study provided critical steps in the process of developing a clinically useful material, there are still many steps left. The most critical will be proving that the surface treatment can produce a material that will allow orthopedic devices to meet the required clinical design constraints.

\section{Acknowledgements}

The authors would like to acknowledge NSF for supporting this work (\#1521188). This was a Phase I STTR awarded to Surface Integrity LLC of which M. Sealy and D. Feldman are officers.

\section{References}

1. Pike C, Birnbaum HG, Schiller M, Sharma H, Burge R, et al. (2010) Direct and indirect costs of non-vertebral fracture patients with osteoporosis in the US. Pharmacoeconomics 28: 395-409.

2. Parker PM (2008) The 2009-2014 world outlook for medical and surgical bone nails, plates, and screws and other internal fixation devices.

3. Elder M (2010) Market research report: advanced orthopedic technologies, implants and regenerative products HLC052B.

4. Anscomb A (2007) Orthopedic biomaterials: world market KLI1399489.

5. Schappert SM, Rechtsteiner EA (2011) Ambulatory medical care utilization estimates for 2007. Vital Health Stat pp: 1-38

6. Ray NF, Chan JK, Thamer M, Melton LJ (1997) Medical expenditures for the treatment of osteoporotic fractures in the United States in 1995: report from the national osteoporosis foundation. J Bone Miner Res 12: 24-35. 
Citation: Sealy MP, Liu Z, Li C, Guo Y, White B, et al. (2017) A Strategy to Optimize Recovery in Orthopedic Sports Injuries. J Bioanal Biomed 9: 144-151. doi:10.4172/1948-593X.1000169

7. Grimm MJ (2009) Orthopedic biomaterials. In: Kutz M (ed.) Biomedical Engineering and Design Handbook (1 ${ }^{\text {st }}$ edn.). McGraw-Hill, NY, USA, pp: 421-444

8. Staiger MP1, Pietak AM, Huadmai J, Dias G (2006) Magnesium and its alloys as orthopedic biomaterials: a review. Biomaterials 27: 1728-1734.

9. Kirkland NT, Birbilis N (2014) Magnesium biomaterials: design, testing, and best practice ( $1^{\text {st }}$ edn.). Springer International Publishing, Cham, Switzerland.

10. Sealy MP, Guo YB, Caslaru RC, Sharkins J, Feldman D (2016) Fatigue performance of biodegradable magnesium-calcium alloy processed by laser shock peening for orthopedic implants. Int J Fatigue 82: 428-436.

11. Sealy MP, Guo YB (2010) Surface integrity and process mechanics of laser shock peening of novel biodegradable magnesium-calcium $(\mathrm{Mg}-\mathrm{Ca})$ alloy. $\mathrm{J}$ Mech Behav Biomed Mater 3: 488-496.

12. Guo Y, Sealy MP, Guo C (2012) Significant improvement of corrosion resistance of biodegradable metallic implants processed by laser shock peening. CIRP Ann-Manuf Techn 61: 583-586.

13. Sealy MP, Guo YB (2011) Fabrication and characterization of surface texture for bone ingrowth by sequential laser peening biodegradable orthopedic magnesium-calcium implants. ASME J Med Devices 5: 011003.

14. Kamkarrad H, Narayanswamy S, Tao XS (2014) Feasibility study of highrepetition rate laser shock peening of biodegradable magnesium alloys. Int $J$ Adv Manuf Technol 74: 1237-1245.

15. Caralapatti VK, Narayanswamy S (2017) Analyzing the effect of high repetition laser shock peening on dynamic corrosion rate of magnesium. Optics Laser Tech 93: 165-174.

16. Xiong $\mathrm{Y}$, Hu Q, Song R, Hu X (2017) LSP/MAO composite bio-coating on AZ80 magnesium alloy for biomedical application. Mater Sci Eng C Mater Biol Appl 75: $1299-1304$

17. Zhang Y, You J, Lu J, Cui C, Jiang Y, et al. (2010) Effects of laser shock processing on stress corrosion cracking susceptibility of AZ31B magnesium alloy. Surf Coat Tech 204: 3947-3953.

18. Salahshoor M, Guo YB (2014) Biodegradation control of magnesium-calcium biomaterial via adjusting surface integrity by synergistic cutting-burnishing. Procedia CIRP 13: 143-149.

19. Salahshoor M, Guo YB (2011) Surface integrity of biodegradable magnesiumcalcium orthopedic implant by burnishing. J Mech Behav Biomed Mater 4 : 1888-1904.

20. Salahshoor M (2013) Process mechanics in ball burnishing biomedical magnesium-calcium alloy. Int J Adv Manuf Technol 64: 133-144.

21. Fouad Y, El Batanouny M (2011) Effect of surface treatment on wear behavior of magnesium alloy AZ31. AEJ 50: 19-22.

22. Fouad $Y$ (2011) Fatigue behavior of a rolled $A Z 31$ magnesium alloy after surface treatment by EP and BB conditions AEJ 50: 23-27.

23. Hilpert $M$, Wagner $L(2000)$ Corrosion fatigue behavior of the high-strength magnesium alloy AZ 80. J Mater Eng Perform 9: 402-407.

24. Pu Z, Song GL, Yang S, Outeiro JC, Dillon OW, et al. (2012) Grain refined and basal textured surface produced by burnishing for improved corrosion performance of AZ31B Mg alloy. Corros Sci 57: 192-201.

25. Zhang $P$, Lindemann J (2005) Influence of shot peening on high cycle fatigue properties of the high-strength wrought magnesium alloy AZ80. Scripta Materialia 52: 485-490.

26. Zhang $P$, Lindemann J, Leyens $C$ (2010) Shot peening on the high-strength wrought magnesium alloy AZ80-Effect of peening media. J Mater Process Technol 210: 445-450.

27. Zinn W, Scholtes B (1999) Mechanical Surface Treatments of Lightweigh Materials-Effects on Fatigue Strength and Near-surface Microstructures. J of Materi Eng and Perform 8: 145-151.

28. Liu WC, Dong J, Zhang P, Korsunsky AM, Song X, et al. (2011) Improvement of fatigue properties by shot peening for Mg-10Gd-3Y alloys under different conditions. Mat Sci Eng A 528: 5935-5944.

29. Bhuiyan MS, Mutoh Y, McEvily AJ (2012) The influence of mechanical surface treatments on fatigue behavior of extruded AZ61 magnesium alloy. Mat Sci Eng A 549: 69-75.

30. Dindorf C, Müller C (2003) Corrosion and fatigue behaviour of the magnesium die-cast alloy AZ91 hp after surface treatment, in magnesium anonymous. Wiley-VCH Verlag GmbH \& Co pp: 574-579.

31. Hadzima B, Bukovina M, Doležal $P$ (2010) Shot peening influence on corrosion resistance of AE21 magnesium alloy. Mat Eng 17: 14-19.

32. Mhaede M, Pastorek F, Hadzima B (2014) Influence of shot peening on corrosion properties of biocompatible magnesium alloy $\mathrm{AZ31}$ coated by dicalcium phosphate dihydrate (DCPD). Mater Sci Eng C Mater Biol Appl 39 : 330-335.

33. Barry N, Hainsworth SV, Fitzpatrick ME (2009) Effect of shot peening on the fatigue behaviour of cast magnesium A8. Mat Sci Eng A 507: 50-57.

34. Guo YB, Brooks VS, Todd BA (2010) Characterization of mechanical properties and microstructure of a biomedical magnesium-calcium alloy, medical device materials $\mathrm{V}$.

35. Song G (2011) Corrosion of Magnesium Alloys. Woodhead Publishing Limited Sawston, Cambridge, UK.

36. Guo YB, Sealy MP, Salahshoor M (2015) Biodegradable medical device having an adjustable degradation rate and methods of making the same. US Patent 9084843 B2.

37. Kirkland NT, Lespagnol J, Birbilis N, Staiger MP (2010) A survey of biocorrosion rates of magnesium alloys. Corros Sci 52: 287-291.

38. Hornberger H, Virtanen S, Boccaccini AR (2012) Biomedical coatings on magnesium alloys-a review. Acta Biomater 8: 2442-2455.

39. Zhang C, Zeng R, Liu C, Gao J (2010) Comparison of calcium phosphate coatings on $\mathrm{Mg}-\mathrm{Al}$ and $\mathrm{Mg}-\mathrm{Ca}$ alloys and their corrosion behavior in Hank's solution. Surf Coat Tech 204: 3636-3640.

40. Zhang C, Zeng R, Chen R, Liu C, Gao J (2010) Preparation of calcium phosphate coatings on Mg-1.0Ca alloy. TNMSC 20: s655-s659.

41. Shadanbaz S, Dias GJ (2012) Calcium phosphate coatings on magnesium alloys for biomedical applications: a review. Acta Biomater 8: 20-30.

42. Gu X, Li S, Li X, Fan Y (2014) Magnesium based degradable biomaterials: A review. Front Mat Sci 8: 200-218.

43. Waterman J, Staiger MP (2011) Coating systems for magnesium-based biomaterials-state of the art, in magnesium technology 2011. In: Sillekens WH, Agnew SR, Neelameggham NR, Mathaudhu SN (eds.) Magnesium Technology 2011. John Wiley \& Sons, Inc., Hoboken, NJ, USA, pp: 403-408.

44. Barrere $F$ (2002) Biomimetic calcium phosphate coatings: physicochemistry and biological activity. Dissertation, University of Twente.

45. León B, Jansen J (2009) Thin Calcium Phosphate Coatings for Medical Implants. Springer, NY, USA.

46. Navarro M, Michiardi A, Castaño O, Planell JA (2008) Biomaterials in orthopaedics. J R Soc Interface 5: 1137-1158.

47. Park JB, Bronzino, JD (2002) Biomaterials: principles and applications. CRC Press, Boca Raton, FL, USA.

48. Song GL, Atrens A (1999) Corrosion mechanisms of magnesium alloys. Adv Eng Mater 1: 11-33.

49. Hänzi AC, Gunde P, Schinhammer M, Uggowitzer PJ (2009) On the biodegradation performance of an $\mathrm{Mg}-\mathrm{Y}-\mathrm{RE}$ alloy with various surface conditions in simulated body fluid. Acta Biomater 5: 162-171.

50. McBride ED (1938) Absorbable metal in bone surgery: A further report on the use of magnesium alloys. J Am Med Assoc 111: 2464-2467.

51. Peeters P, Bosiers M, Verbist J, Deloose K, Heublein B (2005) Preliminary results after application of absorbable metal stents in patients with critical limb ischemia. J Endovasc Ther 12: 1-5.

52. Erbel R, Di Mario C, Bartunek J, Bonnier J, de Bruyne B (2007) Temporary scaffolding of coronary arteries with bioabsorbable magnesium stents: a prospective, non-randomised multicentre trial. The Lancet 369: 1869-1875.

53. Brar H, Platt M, Sarntinoranont M, Martin P, Manuel M (2009) Magnesium as a biodegradable and bioabsorbable material for medical implants. JOM 61: 31-34.

54. Castellani C, Lindtner RA, Hausbrandt P, Tschegg E, Stanzl-Tschegg SE (2011) Bone-implant interface strength and osseointegration: Biodegradable magnesium alloy versus standard titanium control. Acta Biomater 7: 432-440.

55. Erdmann N, Bondarenko A, Hewicker-Trautwein M, Angrisani N, Reifenrath $\mathrm{J}$, et al. (2010) Evaluation of the soft tissue biocompatibility of $\mathrm{MgCaO} .8$ and surgical steel $316 \mathrm{~L}$ in vivo: a comparative study in rabbits. Biomed Eng Online 9: 63-79.

56. Heublein B, Rohde R, Kaese V, Niemeyer M, Hartung W, et al. (2003) Biocorrosion of magnesium alloys: a new principle in cardiovascular implant technology? Heart 89: 651-656. 